\title{
A Study on the Impact of Rural Electrification on the Agricultural Productivity in MIMAROPA-Region 4B, Philippines
}

\author{
Jennylyn Frances E. Dugasan ${ }^{1}$ \\ Jennifer Jane S. Napallatan' ${ }^{1}$ iD \\ Fei Dhania V. Nip ${ }^{1}$ \\ Ronaldo R. Cabauatan ${ }^{1,9,3,4}$ (iD
}

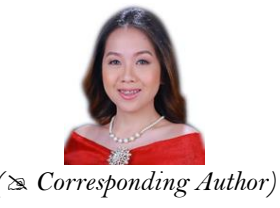

College of Commerce of Business Administration, University of Santo Tomas, Manila, Philippines.

Research Center for Social Sciences and Education, University of Santo Tomas, Manila, Philippines.

The Graduate School, University of Santo Tomas, Manila, Philippines.

${ }^{4}$ Social Sciences Division, National Research Council of the Philippines.

Email:jennylynfrances.dugasan.comm@ust.edu.ph Tel:09218332216

'Email: janenapallatan@gmail.com Tel:09676149711

Email:dhaniafeidvn@gmail.com Tel:09663989559

,e,s, Email: rrcabauatan@ust.edu.ph

\section{Abstract}

This study examines the effect of rural electrification to agricultural productivity in the MIMAROPA-Region 4B, Philippines. Rural electrification is said to have a significant benefit particularly in agricultural productivity. There are several challenges among the implementation of rural electrification. Low rural incomes can make it difficult to afford and long distances mean more power losses, as well as costly customer service and equipment maintenance. This research proves that rural electrification positively affects agricultural productivity. A multiple regression analysis will be used to evaluate the data to be obtained and determine the relationship between the regressors and the dependent variable. For this study, the independent variables are the percentage of rural electrification (RE), cost of electricity (CE), and the period of democracy (PD). Meanwhile, the dependent variable is agricultural productivity (AP). The data will be sourced from various government agencies in the Philippines including Energy Regulatory Commission, Department of Agriculture MIMAROPA, and Philippine Statistics Authority MIMAROPA.

Keywords: Rural electrification, Agriculture, Agricultural productivity, Cost of electricity, Period of democracy, Labor productivity. JEL Classification: O18, Q10, O40, D24, A 10, J24.

Citation | Jennylyn Frances E. Dugasan; Jennifer Jane S. Napallatan; Fei Dhania V. Nip; Ronaldo R. Cabauatan (2022). A Study on the Impact of Rural Electrification on the Agricultural Productivity in MIMAROPA-Region 4B, Philippines. Asian Journal of Social Sciences and Management Studies, 9(1): 18-24. History:

Received: 22 December 2021

Revised: 24 January 2022

Accepted: 7 February 2022

Published: 16 February 2022

Licensed: This work is licensed under a Creative Commons

Attribution 3.0 License $(\mathrm{cc}) \mathbf{E Y}$

Publisher: Asian Online Journal Publishing Group
Funding: This study received no specific financial support.

Authors' Contributions: All authors contributed to the conception and design of the study.

Competing Interests: The authors declare that they have no conflict of interests.

Transparency: The authors confirm that the manuscript is an honest, accurate, and transparent account of the study; that no vital features of the study have been omitted; and that any discrepancies from the study as planned have been explained.

Ethical: This study followed all ethical practices during writing.

\section{Contents}

1. Introduction

2. Review of Related Literature ............ 20

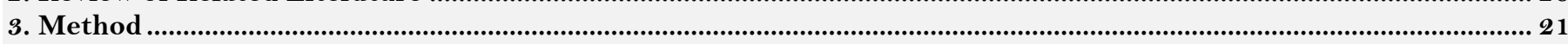

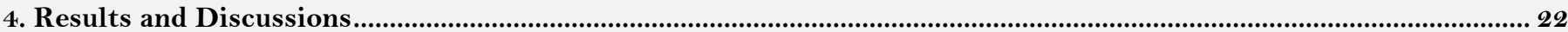

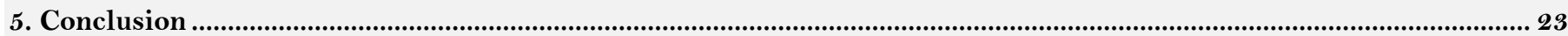

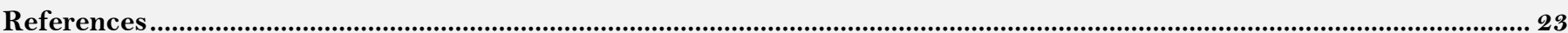




\section{Contribution of this paper to the literature}

This study contributes to the small range of rural electrification literature in the agricultural sector of the Philippines. It focuses on the positive and negative effects of inaccessible and scarce resources of electricity in certain far-flung areas in the country where households mostly engage in agricultural activities.

\section{Introduction}

In the Philippines, agriculture is the way of living and means of support for most rural communities; for decades it was proven that agriculture is still one of the most reliable sources of income for the Filipinos. A simple supply of light from one electric bulb can alter the community's way of living, interactions within the neighborhood, and this conclusively entails that their quality-of-life increases. The type of source used in the agricultural production process is very significant and most rural farmers include their families, as well as some members of their community as their own laborers where they frequently use traditional farming tools rather than electric machines used for agriculture. As rural electrification programs progressed in the Philippines for many years, it was constantly assumed that mere provision of electricity supply in rural areas can efficiently increase their incomes. This is attributed to many factors, and one of these is that electricity is seen as an energy modem which is important for growth. In most regions of the country, electricity-free zones are much less advanced than access areas. Electricity serves many purposes in rural areas such that it will increase efficiency for businesses and farmers, reduce the cost of household work and offer rural families more effective lighting. Electricity can theoretically change living conditions and enhance economic growth. Providing access to these rural farmers undoubtedly improves their living conditions, develops their farming techniques in the most efficient way, and adequate electricity supply is seen to create more opportunities for these small-time farmers.

Looking at the rural households that are engaged in agricultural activities that often require electricity to operate the farmers' modern farm machinery and irrigation systems. Without an adequate and reliable electricity supply, rural households that are inclined with agricultural jobs are at disadvantage and may be subjected to low productivity, hence, low income as well. In the absence of adequate and reliable sources of electricity, these rural households that are into agriculture are on the side of disadvantage from reduced labor costs, new farming technologies, more sustainable strategy, and means to alleviate poverty. Indirectly, access to electricity impacts agricultural productivity such that electricity plays a crucial role in increasing the value added captured by farmers by being able to store their crops and products sustainably and in obtaining information on market conditions that affects the decision making of the farmers through information communication technology (ICT) (Sovacool, 2012). In the means of reducing and alleviating poverty in the Philippines, several government agencies have launched several rural electrification programs all over the country. Recently, the National Electrification Administration (NEA) have extended over P123 million in April 2021 that is purposely for the improvement of rural electrification infrastructure of electric cooperatives with the country. With this being said, the provision and implementation of rural electrification programs and infrastructures in the country shows how vital electricity supply is to these rural households that are engaged in agriculture in rural areas most specifically in MIMAROPA-Region $4 \mathrm{~b}$ in the Philippines that are seen to have one of the lowest numbers of electrified rural areas. The Philippine Department of Energy stated that MIMAROPA is still one region with the largest number of un-electrified barangays. As a result, the DOE has increased the generation of renewable energy in the region, especially in Mindoro and Palawan, which are two off-grid islands. Consequently, according to National Electrification Administration Philippines, there are only four (4) electric cooperatives that are mainly serving and providing electricity supply to Mindoro and Palawan which are 1) Lubang Electric Cooperative (LUBELCO) and 2) Occidental Electric Cooperative OMECO), both are supplying electricity to Mindoro. In addition to that the two electric cooperatives that are serving Palawan are 1) Busuanga Island Electric Cooperative (BISELCO) and 2) Palawan Electric Cooperative (PALECO). To advance the goal of the country's total electrification, several Philippine government agencies such as Department of Energy (DOE), Energy Regulatory Commission (ERC), and National Electrification Administration (NEA) crafts and designs policies and programs in order to intensify the provision of supplying adequate and reliable source of electricity via powering through use of renewable energy mini-grids to the two off-grids Islands which is Mindoro and Palawan.

The programs related to rural electrification are implemented on the widely held belief that having access to electricity would improve household well-being and increase rural productivity. Only in the last decade or so has a growing body of impact assessment studies begun to quantify such impacts. In developing countries, rural electrification is often the chosen program for fostering equity and economic growth. Electricity is regarded as a modern source of energy in most parts of the world, and areas without it are far less developed than those who have it. Despite improvements in access to electricity, the Philippines still suffers from energy shortages. To meet the country's rising demand for electricity, the country is heavily reliant on coal power and large-scale transmission lines; although the country aims to supply electricity to towns, rural areas are falling behind. This strategy has resulted in higher energy prices, disparities in electricity delivery between urban and rural areas, and a significant environmental effect, all while putting the system's efficiency at risk (Jimenez, 2017). Considering the objective of rural electrification programs and that is to provide adequate, reliable, and affordable electricity services in the country, generating and prioritizing provisions that upholds this objective leads to socio-economic development and accelerates the growth of the economy.

In the Philippines, rural electrification acts as the driving force behind sustainability in terms of income, health, and education, that benefits rural agricultural production, and this has been shown to have positive impacts on communities. Advancing electricity lines in rural areas have been synonymous with supplying the facilities needed for rural areas to develop rapidly. In general, the rise in agricultural productivity is seen as the effect of technical changes, including the development of new farming practices. This chapter will review the role and relation of rural electrification to agricultural productivity particularly in the rural areas in MIMAROPA-Region 4B, Philippines, in which the mostly agricultural economy was affected by electrification, the increased employment rate, and rural farm population. Rural electrification carries a lot of beneficial factors that are known to improve the quality of life. It greatly impacts the agricultural sector, as well as the households, and it also comprehensively 
stimulates socio-economic development. With this being said, there is a need to look at the impacts of rural electrification. Theoretically, this study would further enhance the understanding of impacts on rural electrification, the factors affecting it, and how it also affects rural productivity.

The purpose of this paper is to whether rural electrification positively or negatively impacts the agricultural productivity of the MIMAROPA-Region $4 \mathrm{~B}$ with the objectives of $(1)$ to collect significant data that shows if rural electrification can help agricultural productivity positively or negatively, (2) to explore the underlying factors of rural electrification throughout the years and know how it affects the agricultural productivity in MIMAROPARegion $4 \mathrm{~B},(3)$ to assess effects of rural electrification to agricultural productivity of the MIMAROPA-Region $4 \mathrm{~B}$, and (4) to propose recommendations to policymakers that would greatly affect the agricultural productivity of the MIMAROPA-Region 4B, Philippines.

This study intends to contribute to a growing socio-political and socio-economic literature with regards to rural electrification in developing countries. The findings of this study and recommendations are practically useful for the following: (1) in developing evidence that are based on policies, (2) for the policy makers who are responsible in defining objectives for energy and rural electrification programs, and (3) to strengthen systematic institutional frameworks that is critically essential in optimal planning of rural development. Additionally, the assessments conducted, and the results of this study should be taken into consideration when it comes to designing short-run and long-term policies that will be used for rural development, as well as for the progress of the Agricultural sector in the Philippines; these can be used to project and stimulate future alternative plans for the sector. Consequently, these projections can be utilized for the evaluation of what the Agricultural sector can play in the future development of the Philippine economy.

\section{Review of Related Literature}

Empirical studies over the years that have assessed whether hypothesized effects of rural electrification are perceived in actuality. In recent years there have been multiple attempts to present these studies in a larger manner to be able to draw wider conclusions regarding the impacts of electrification (Litzow, Pattanayak, \& Thinley, 2019). The Philippines is highly dependent on coal power and large-scale transmission lines to meet its growing demand for electricity, while aiming to supply electricity to the cities, and rural areas. Various actions under the United Nations Development Program have improved the electrification rate in rural areas (Taniguchi, 2019). Access to electricity in rural areas is likely to encourage agricultural farmers to adopt practices and strategies that can enhance agricultural productivity and can increase profits (Chindarkar, Chen, \& Sathe, 2020).

According to Litzow et al. (2019), Rural Electrification (RE) programs were implemented with the intention to improve agriculture, education, health, and employment outcomes in rural areas. From a consumer's perspective, the country has seen remarkable progress. Because of the government's ambitious goals and strenuous efforts, the electricity access rate has improved dramatically over the past decades. The Philippines is one of the more advanced countries in the Southeast Asian region in terms of household electrification (DOE Philippines, 2016b). Over the past few years, there are comparatively several studies to assess the role of rural electrification to rural development as it was considered as an expense and of limited effectiveness in rural areas.

The predominant aspect that most studies focused on is on how lack of access to electrification in rural areas may affect the quality of life specifically on agricultural productivity, education, households, and employment. Brandon, Dadhi, and Matías (2016); Litzow et al. (2019). The validity of correlation between rural electrification and welfare outcomes is seen as one of the important objectives of the existing studies (Khandker, Barnes, \& Samad, 2013). Additionally, the relationship between rural electrification programs and growth has become one the most recognized study that relates to the country's level of development and the most evident direct outcome is through the productivity effect of the country (Cook, 2011).

According to the Missionary Electrification Plan 2012, the Small Power Utilities Group (SPUG) will no longer be operating in new locations within 5 years after its release. However, only missionary regions classed as Small A areas are being provided with generating services. The role of the future SPUG shall be reduced to the Universal Charge applicant and disburser for electrification mission and system manager on huge islands and isolated networks such as permitted pursuant to the Philippine Small Grid Guidelines, Palawan and Mindoro may.

Many general studies in this field that have been conducted are mainly concentrated on the relation between rural electrification and development yet, there are still few studies that are rigorously focused on the causal relationship of rural electrification and agricultural productivity. Most of the existing evidence is typically examined and measured through the impact of rural electrification programs by comparing several households with or without electricity in particular rural areas. Such evaluations generally have not measured the extent and nature of the accrued benefits of these said programs (Khandker et al., 2013). Furthermore, a set of studies assess the outcomes of (RE) programs through community-level effects of electrification such as schools and farms that have access to electricity. In relation to this, recent studies suggest that electrification can trigger significant changes in the economy (Chakravorty, Emerick, \& Ravago, 2016). Majority of the current studies focus on the long-term impacts of rural electrification on household consumption and air quality, manufacturing firms and agricultural production and nearly all previous studies center on estimating and measuring the benefits that rural electrification brings to different sectors. In this chapter, the researchers review the literature that are mainly focused on the role and relation of rural infrastructure and rural electrification programs to the economy's growth and development.

The agricultural sector, as well as its energy inputs, are the subject of this section. To examine both the energy needs for agriculture and the requirements for rural energy services in the Philippines, as well as some islands with mini grids such as Mindoro, Catanduanes and Sibuyan Islands in the last decade. The main islands of Palawan and Mindoro were already being served by the SPUG with continuous electricity (Electric Power Industry Reform Act). It is useful to consider three entry levels for interventions. The "energy ladder" method encompasses these three stages. The three-stage evolution of agriculture can be summarized as follows: (1) The use of animal work to provide various energy inputs, (2) simple human work for crop rotation, harvesting, and processing, as well as rainfed irrigation, none of which require an external fuel source, and (3) the use of renewable energy technology such as wind pumps, solar dryers, and water wheels in conjunction with modern renewable and fossil fuel-based technologies for motive and stationary power applications, as well as for agricultural product processing. The 
needs of poor people in rural areas can be thought of on three levels when it comes to energy: (1) Traditional biomass fuels are used for basic survival in cooking, illumination, and space heating, (2) as people progress beyond subsistence, alternative biomass fuels such as kerosene and LPG are used in these applications, and (3) enhanced electricity systems in rural areas using modern renewable energy and fossil fuels, such as supplying energy for small electrical appliances (such as lighting and radio) and community facilities (e.g. street lighting, water pumping, power for health centers and schools).

In the Philippines, rural communities have a greater ratio of low-income households who suffer from high cost of electricity and upfront capital costs needed for energy efficiency improvements. Cost of electricity can influence agricultural production (Sands \& Westcott, 2011). Electricity is a crucial input in agriculture. Agriculture uses energy directly on the farm in the form of fuel or electricity to run machinery and equipment, heat or cool houses, and light, as well as indirectly in the fertilizers and chemicals generated off the farm. The cost of electricity, as a result, has an effect on agricultural production in MIMAROPA-4B due to the rise in electricity prices would decrease agricultural productivity as rural communities could not afford high pricing and which would affect the usage of equipment needed, increase agricultural product prices, and decrease farm income (Department of Energy).

It is commonly believed that democracy influences public service provisions, and this includes policies that are proposed and implemented in rural areas. Trotter (2016) suggested that democracy is strongly associated with rural electrification increases and it shows that inequality between rural and urban electrification decreases.

In general, providing electricity is highly capital intensive (Trotter, 2016). With the implementation of provisions solely based in accordance with the public's interest which includes rural electrification might increase agricultural productivity (Trotter, 2016). It is evident that in democracies, higher political incentives provide an extension of electricity infrastructure in rural areas that are previously unserved rather than just developing the existing electricity grid infrastructure to improve reliability (Trotter, 2016).

The overall empirical findings of the review of literature shows a close correlation between rural infrastructure and agricultural productivity. Agriculture efficiency is affected by factors such as electricity and roads. Since paved roads, village irrigation, and microcredit participation are all binary variables in our study, households either received or did not receive these policies, as opposed to the difference in household benefits from percentage increases in village electrification and production prices. We discover that electricity has little effect on employment, meaning that an increase in labor force participation is not the relevant mechanism.

The effect of rural electrification on agriculture productivity is positive. This concludes that agricultural productivity is increasing, and the local economy is expected to be affected by potential channels. (1) a rise in agricultural productivity and (2) developments in rural housing quality. Any impact would improve a country, driving upland, and property values (Haanyika, 2006). Hornbeck and Keskin (2015) believed that a temporary improvement of rural electrification's agricultural output will also promote broad local growth through the local agglomeration forces as well as spillover productivity. For example, an expansion in the agricultural sector could increase demand for non-traded goods supplied by the local industrial sector. Similarly, an increase in local infrastructure may also have a spillover effect on non-agricultural sectors. If electricity increases production, governments and policymakers must concentrate on further investment to increase the sector such that when the communities receiv electricity, productivity will not drop. It is expected that land, labor, capital, electrification, and institutional quality would increase agricultural output (Khandker, Samad, Ali, \& Barnes, 2012).

\section{Method}

This study used a quantitative research approach within different phases of the research to collect and analyze data. Quantitative data will be collected as an offset approach of research method strategy (Bryman, 2008) to analyze, converge, and validate findings from data depending on the nature of the research questions in a complementary manner. The main outcome variables of this study are rural electrification the percentage of electrified rural areas), cost of electricity, and the period of democracy as the dummy variable. Moreover, this study will be using regression analysis to quantify the variables used in this study. This statistical method can provide a better understanding and analysis of the underlying impact of Rural Electrification in the Agricultural Productivity of Region 4B-MIMAROPA based on panel data of rural areas monthly from the years 2015-2017 sourced from various government agencies in the Philippines including Energy Regulatory Commission, Department of Agriculture MIMAROPA, and Philippine Statistics Authority MIMAROPA.

A multiple regression analysis used to evaluate the data and determine the relationship between the regressors and the dependent variable. For this study, the independent variables are the percentage of rural electrification $(\mathrm{RE})$, cost of electricity (CE), and the period of democracy (PD). Meanwhile, the dependent variable is agricultural productivity (AP). This will be the equation model:

$$
A P=\beta_{0}+\beta_{1} R E_{i}-\beta_{2} C E_{1}+\beta_{3} P D_{i}+e
$$

\subsection{Augmented Dickey-Fuller (ADF)}

Most economic time series data have unit roots which show that their means and variances are not timeinvariant. If this is the case, a univariate series is said to be non-stationarity and cannot be used for regression with other non-stationary univariate series because of the risk that their results maybe spurious. The only exception to this rule is when the time series data of all variables have identical unit roots.

The widely used unit root test is the so-called Augmented Dickey-Fuller (ADF) test. The basic equation for testing the stationarity of a time series is given by the following:

$$
\Delta x=\alpha_{o}+\alpha_{t} t+\beta x_{t-i}+\Sigma \varphi \Delta x_{t-i}+\varepsilon_{t}
$$

Where the first difference of the series, $\Delta \mathrm{x}_{\mathrm{t}}$, is regressed against lagged of its original level series, time, and lagged values of itself. If the estimated value of $\beta$ is more negative than MacKinnon critical values, the series is said to be stationary. Otherwise, it is non-stationary and therefore has a unit root. The augmented portion of the test is to correct for any serial correlation in the variable. 


\subsection{Structural Stability Test}

Structural stability test refers to the stability of the coefficients of a regression model between different time periods. In this study, such test will be performed using Chow Breakpoint Test. A structural change could mean a change in the intercept, a change in the slope coefficients, or a change in both the intercept and slope coefficients. Either way, the results would imply structural instability and the model therefore cannot be used for policy analysis and forecasting.

The formula for testing the structural stability of the regression parameter involving time series data is as follows:

$$
F=\frac{\left(R S S_{R}-R S S_{U R}\right) / k}{R S S_{U R} /\left(n_{1}+n_{2}-2 k\right)}
$$

Where $\mathrm{k}$ is the number of regressors including intercept, $\mathrm{n}$ is the number of observations, $\mathrm{RSS}_{\mathrm{R}}$ is the regression sum of squares restricted, and $\mathrm{RSS}_{\mathrm{UR}}$ is the regression sum of squares unrestricted. If the computed Fstatistic exceeds critical value, there is structural instability. Otherwise, the model is said to be structurally stable.

\subsection{Test for Heteroskedastic Disturbances}

If the variance of the regression residuals of the model is time varying, the parameters and their standard errors are said to be biased and inefficient. This condition is known as heteroskedasticity and if uncorrected could lead to wrong conclusions and decisions on the part of the investigator. To detect the presence of heteroskedastic disturbances in the residuals, the White Heteroskedasticity Test will be used.

$$
u^{2}=\alpha_{o}+\alpha_{1} X_{t}+\alpha_{2} X_{2}+\alpha_{s} X_{s}+\alpha_{4} X_{t}^{2}+\alpha_{5} X_{2}^{2}+X_{s}^{2}+\alpha_{6} X_{i} X_{2}+\alpha_{7} X_{1} X_{s}+\alpha_{s} X_{2} X_{s}+v_{t}
$$

Where $u^{2}$ is the squared regression residuals regressed against the explanatory variables, their squares, and cross products.

\subsection{Specification Error Test}

The Ramsey regression equation specification error test (RESET) will be used to test whether non-linear combinations of independent variables help in explaining the dependent variable. This will also help determine if there is no misspecification error in the data used in the study.

A Specification error test is associated with the specification of the model regarding the inclusion of an irrelevant variable, the exclusion of relevant variable, or the functional form of the model. A Specification error creates biased or inconsistent regression estimators, and the inconsistency can still be there even when the sample observation increases. To determine the specification of the model, this study used the equation:

$$
\hat{Y}_{i}=\hat{\beta}_{1}+\hat{\beta}_{2} X_{2 i}+\hat{\beta}_{3} X_{3 i}+\gamma \widehat{Y}_{i}^{2}
$$

\section{Results and Discussions}

For this study, a multiple regression analysis was used to evaluate the data to be obtained and determine whether rural electrification positively or negatively impacts the agricultural productivity of the MIMAROPARegion 4B. The independent variables are the percentage of rural electrification (RE), cost of electricity (CE), and the period of democracy (PD). Meanwhile, the dependent variable is agricultural productivity (AP). The equation model used was: $A P=\beta_{0}+\beta_{1} R E_{i}-\beta_{2} C E_{1}+\beta_{3} P D_{i}+e$. This study is a regional study and was solely conducted in region $4 \mathrm{~B}-\mathrm{MIMAROPA}$, Philippines. This study used the first difference of Agricultural Productivity and the

\begin{tabular}{|c|c|c|c|c|c|}
\hline \multicolumn{6}{|c|}{ Dependent variable: $\mathrm{d}$ (Agricultural Productivity) } \\
\hline Regression Statistics & Coefficient & Std. Error & t-ratio & p-value & Significant Level \\
\hline Constant & 2.78 & 1.05 & 2.64 & 0.01 & *** \\
\hline dlog(Rural Electrification) & 866 & 581 & 1.49 & 0.14 & \\
\hline Cost of Electricity & -459 & 173 & -2.65 & 0.01 & *** \\
\hline R-squared & 0.20 & \multicolumn{2}{|c|}{ Adjusted R-squared } & \multicolumn{2}{|c|}{0.15} \\
\hline $\mathrm{F}(2,28)$ & 3.67 & \multicolumn{2}{|c|}{ P-value $(\mathrm{F})$} & \multicolumn{2}{|c|}{0.03} \\
\hline $\mathrm{F}(3,25)$ & 0.22 & \multicolumn{2}{|c|}{ Durbin-Watson } & \multicolumn{2}{|c|}{2.05} \\
\hline $\mathrm{P}($ Chi-square $(5)>0.571692)$ & 0.98 & \multicolumn{2}{|c|}{$\mathrm{P}(\mathrm{F}(2,26)>0.00515687)$} & \multicolumn{2}{|c|}{0.99} \\
\hline
\end{tabular}
$\log$ first difference of Rural Electrification upon testing the data.

Table 1. Ordinary least squares (OLS) model.

Note: $(1) \mathrm{d}=$ First difference; $\mathrm{dlog}=$ First difference of $\log$.

(2) The coefficients with ** statistically significant at the $5 \%$ level, respectively, when the test is applicable.

Table 1 presents the relationship and significance of Agricultural productivity and a set of independent variables namely Rural Electrification and Cost of Electricity. The Cost of Electricity is significant at $5 \%$ alpha. However, the log first difference of Rural Electrification is insignificant. For rural electrification, an increase in the percentage of electrified rural areas doesn't affect the agricultural productivity in region 4B-MIMAROPA. On the other hand, when cost of electricity increases, agricultural productivity in region 4B-MIMAROPA decreases. The cost of electricity, as a result, would decrease agricultural productivity as rural communities could not afford high pricing and which would affect the usage of equipment needed, increase agricultural product prices, and decrease farm income.

In addition, it is seen as significant as the p-value of $\mathrm{F}$-test which is equal to 0.0000 that satisfies the condition wherein the p-value must be less than or equal to the level of significance of 0.05 . The p-value 0.2275 denotes that there is no structural break error. Accept null hypothesis as the calculated F-critical values. The p-value in White's test for heteroskedasticity is 0.98926. It is greater than the default level of significance which is 0.05. This means that there is no heteroskedasticity error. The Specification Error Test or also known as the RESET specification test is used to assess the adequacy or acceptability of the functional form. This means that the functional form should be adequate for it to be the null hypothesis and that the alternative is not. This test includes running several 
regressions and computing of the F-statistic. The p-value in RESET specification test for is 0.995. It is greater than the default level of significance which is 0.05. This means that there is no misspecification error.

Table 2. Augmented dickey-fuller (ADF) test.

\begin{tabular}{l|c|c|c|c|c|c}
\hline Variables & $\begin{array}{c}\text { Level } \\
\text { with } \\
\text { constant }\end{array}$ & $\begin{array}{c}\text { Level } \\
\text { with } \\
\text { constant } \\
\text { and Trend }\end{array}$ & $\begin{array}{c}\text { First } \\
\text { Difference } \\
\text { with } \\
\text { constant }\end{array}$ & $\begin{array}{c}\text { First } \\
\text { Difference } \\
\text { with constant } \\
\text { and Trend }\end{array}$ & $\begin{array}{c}\text { Second } \\
\text { Difference } \\
\text { with constant }\end{array}$ & $\begin{array}{c}\text { Second } \\
\text { Difference } \\
\text { with constant } \\
\text { and Trend }\end{array}$ \\
\hline Agricultural productivity & 0.00 & 0.01 & 0.00 & 0.00 & 0.00 & 0.00 \\
\hline Cost of electricity & 0.00 & 0.00 & 0.00 & 0.00 & 0.00 & 0.00 \\
\hline Rural electrification & 0.29 & 0.38 & 0.00 & 0.00 & 0.00 & 0.00 \\
\hline
\end{tabular}

Table 2 displays the standard errors of the variables, monitored over a specific amount of time, that are nonconstant. The unit test root for the dependent variable which is the Agricultural productivity has an asymptotic pvalue of 0.0005755 with test statistic of -4.73157 . Moving to the independent variables, first is the Cost of Electricity that shows its unit test root that has an asymptotic p-value of 1.332e-007 with test statistic of -8.10129. On the next variable, it shows the unit test root of Independent Variable Rural Electrification with asymptotic pvalue of 0.3885 with test statistic of -2.36727 . These results shows that the researchers reject the null hypothesis that there is a unit root with an alpha of 0.05. Moreover, the Test Statistics of the dependent variable and the independent variables appears to be all negative which provides stronger evidence for rejecting the null hypothesis of a unit root.

\section{Conclusion}

The study obtained that indeed, rural electrification positively affects the agricultural productivity of region 4B-MIMAROPA Philippines. Access to low-cost electricity will provide rural households in the said region with feasible options for production, processing, marketing, and distribution. Thus, it will help create the conditions for improved agricultural productivity. The Philippines' power rates are much higher than those of neighboring ASEAN countries and this situation has constrained the competitiveness of local and foreign firms operating in the country. A joint Asian Development Bank (2005) survey found that electricity (33\%) was considered by businessmen as the most critical constraint compared with transport (18\%) and telecommunications (10\%). Losses owing to power failure amounted, on average, to $8 \%$ of production. Power outages hurt small and medium-size firms most, costing them an equivalent of about $8 \%$ and $11 \%$ of production, respectively, compared with $6 \%$ for large firms.

The Philippines is one of the more advanced countries in the Southeast Asian region in terms of household electrification (DOE Philippines, 2016b) and based on the data acquired by the researchers, it was in fact true that the country has seen a remarkable progress because of the government's ambitious goals and continuous efforts to implement electrifying programs to rural areas in the country. Also, the electricity access rate has improved over the past decades. Thus, this paper supports the existing studies of Litzow et al. (2019), wherein it was stated that Rural Electrification (RE) programs were implemented with the intention to improve agriculture, education, health, and employment outcomes in rural areas and that electrification can trigger significant changes in the economy (Chakravorty et al., 2016). The researchers also proved that the percentage of rural households with electricity and the period of democracy positively and directly impacts the agricultural productivity of the sector through similar studies from Khandker et al. (2012) that it is expected that land, labor, capital, electrification, and institutional quality would increase agricultural output and from Trotter (2016) that with the implementation of provisions solely based in accordance with the public's interest which includes rural electrification might increase agricultural productivity, respectively. On the other hand, the researchers also acquired evidence statements from the Department of Energy (DOE) Philippines (2016a) that the cost of electricity has an effect on agricultural production due to the rise in electricity prices would decrease agricultural productivity as rural communities could not afford high pricing that can decrease their income.

The study recommends that results suggest that rural areas with limited electricity availability and sourcing electricity exhibit low agricultural production, while some rural areas that have access and sourcing electricity from cleaner energy resources tend to show higher agricultural production growth. Electrification in in region 4BMIMAROPA is a crucial element in achieving agricultural production growth. Providing electricity access to the rural communities is seen to support economic growth and development. Policymakers should focus on the sustained implementation of the policy reform program, which includes as key elements the privatization of the National Power Corporation (NPC), an efficient regulation of the electricity market, and the creation of an attractive environment for private investors in the generation segment of the market. The effectiveness of several electrification projects for rural areas in MIMAROPA Region-4B has been a challenge due to a number of factors, including the issues on affordability, capacity, and reliability.

\section{References}

Asian Development Bank. (2005). Assessing the impact of transport and energy infrastructure on poverty reduction. ADB Report.

Brandon, A. B., Dadhi, A., \& Matías, F. (2016). Electricity, income, and quality of life. The Social Science Journal, 53(1), 33-39.Available at: https://doi.org/10.1016/j.soscij.2014.12.009.

Bryman, A. (2008). Social research methods (3rd ed.). New York: Oxford University Press.

Chakravorty, U., Emerick, K., \& Ravago, M. L. (2016). Lighting up the last mile: The benefits and costs of extending electricity to the rural poor. Resources for the Future Discussion Paper, No.16-22.

Chindarkar, N., Chen, Y. J., \& Sathe, S. (2020). Link between farm electricity supply management, farm investments, and farm incomesevidence from India. Energy Policy, 141, 111407 .Available at: https://doi.org/10.1016/j.enpol.2020.111407.

Cook, P. (2011). Infrastructure, rural electrification and development. Energy for Sustainable Development, 15(3), 304-313.Available at: https://doi.org/10.1016/j.esd.2011.07.008.

Department of Energy (DOE) Philippines. (2016a). Philippine energy plan 2016-2030. Republic of the Philippines Department of Energy. Retrieved from https://www.doe.gov.ph/pep/philippine-energy-plan-2016-2030. 
DOE Philippines. (2016b). 2016 Philippine power situation report. Republic of the Philippines department of energy. Retrieved from: https://www.doe.gov.ph/electric-power/2016-philippine-power-situation-report.

Haanyika, C. M. (2006). Rural electrification policy and institutional linkages. Energy Policy, 34(17), 2977-2993.

Hornbeck, R., \& Keskin, P. (2015). Does agriculture generate local economic spillovers? Short-run and long-run evidence from the Ogallala Aquifer. American Economic Journal: Economic Policy, 7(2), 192-213.

Jimenez, R. (2017). Development effects of rural electrification. Inter-American Development Bank.

Khandker, S., Barnes, D., \& Samad, H. (2013). Welfare impacts of rural electrification: A panel data analysis from Vietnam. Economic Development and Cultural Change, 61(3), 659-692.Available at: https://doi.org/10.1086/669262.

Khandker, S., Samad, H., Ali, R., \& Barnes, D. (2012). Who benefits most from rural electrification? Evidence in India. The Energy Journal, 35 , 1-40.Available at: https://doi.org/10.5547/01956574.35.2.4.

Litzow, E. L., Pattanayak, S. K., \& Thinley, T. (2019). Returns to rural electrification: Evidence from Bhutan. World Development, 121, 7596.Available at: https://doi.org/10.1016/j.worlddev.2019.04.002.

Sands, R., \& Westcott, P. (2011). Impacts of higher energy prices on agriculture and rural economies. United States Department of Agriculture: Economic Research Report No. 123.

Sovacool, B. K. (2012). Design principles for renewable energy programs in developing countries. Energy Eீ Environmental Science, 5(11), 9157-9162.

Taniguchi, S. (2019). Securing access to electricity with variable renewable energy in the Philippines: Learning from the Nordic model: ADBI Working Paper Series (No. 1009).

Trotter, P. (2016). Rural electrification, electrification inequality and democratic institutions in Sub-Saharan Africa. Energy for Sustainable Development, 34, 111-129.Available at: https://doi.org/10.1016/j.esd.2016.07.008. 